\title{
Complexation of some Hydrazones Bearing the Quinoline Ring. Potentiometric Studies
}

\author{
H. S. Seleem, * G. A. El-Inany, M. F. Eid, M. Mousa and F. I. Hanafy \\ Department of Chemistry, Faculty of Education, Ain Shams University, Roxy, Cairo, Egypt
}

Três hidrazonas (oxímica: MHQ, cetônica: BHQ e fenólica: AHQ) contendo o anel quinolínico foram preparadas e caracterizadas. As suas constantes de dissociação e as constantes de estabilidade dos seus complexos com alguns íons de metais de transição, lantanídeos e actinídeos foram determinadas potenciometricamente em dioxano-água $75 \%$ (v/v) a $303 \mathrm{~K}$. Adicionalmente, constantes de estabilidade de cobaloximas (complexos $\mathrm{Co}^{\mathrm{II}}-\mathrm{MHQ}$ ) foram determinadas a $303 \mathrm{~K}$ em solvente-água $75 \%(\mathrm{v} / \mathrm{v})($ solvente= dioxano, isopropanol, etanol e metanol) e em 75, 70, 65, 60 e 55\% (v/v) etanol-água. Uma análise de regressão linear foi usada para a estimativa das constantes de estabilidade em meio aquoso. A ordem de estabilidade de Irving-Williams não é obedecida rigorosamente.

Three hydrazones (oximic: MHQ; ketonic: BHQ and phenolic: AHQ) bearing the quinoline moiety were prepared and characterized. Their dissociation constants as well as their stability constants with some transition, lanthanide and actinide metal ions have been investigated potentiometrically in $75 \%(\mathrm{v} / \mathrm{v})$ dioxane-water at $303 \mathrm{~K}$. Also, stability constants of cobaloximes in $75 \%(\mathrm{v} / \mathrm{v})$ solvent-water (solvent = dioxane, isopropanol, ethanol and methanol) as well as in $75,70,65,60$ and $55 \%$ (v/v) ethanol-water at $303 \mathrm{~K}$ were evaluated. A linear regression analysis was used to evaluate the stability constants in the aqueous medium. Irving-Williams order for stability is not strictly obeyed.

Keywords: hydrazones, quinoline, stability constants

\section{Introduction}

Hydrazones are compounds derived from the condensation of hydrazines with carbonyl compounds, namely aldehydes and ketones. Hydrazones are known to function as chelating agents. These compounds can display antitubercular effects, ${ }^{1}$ based on their tendency to form metal chelates with transition metal ions. The reaction of aroylhydrazones with transition metal ions can proceed according to two pathways attaining the ketonic or enolic structure for the hydrazide part of the molecule (Scheme 1).

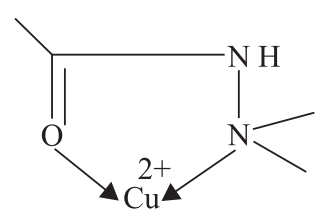

Ketonic

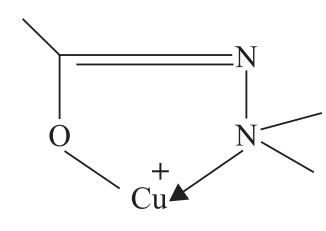

Enolic
Scheme 1.

* e-mail: hsseleem@yahoo.com
The mode of bonding depends on the nature of both the ligand and metal ions, the anion of the metal salt and the solvent used. ${ }^{2,3}$ Furthermore, some hydrazones are used as quantitative analytical reagents, especially in colorimetric and fluorimetric determinations of metal ions. ${ }^{4}$ Based on the previous studies, ${ }^{5,6}$ the extent of $\mathrm{p}_{\pi}-\mathrm{d}_{\pi}$ interaction between the hydrazone group and the central metal ion is determined by the type and position of the different substituents relative to the parent hydrazino compound. Also, the stability of the hydrazone chelates is higher than that of the corresponding hydrazino compounds and depends on the different substituents. In addition, the hydrazones bearing the triazine ring have the highest reactivity towards the various metal ions.

In our previous studies, ${ }^{7-13}$ the chelating ability of some hydrazones bearing the pyridazine, pyrimidine and triazine rings was investigated in solution as well as in the solid state. In the present study, these investigations were extended to the hydrazones bearing the quinoline ring. This article deals with dissociation and stability constants of three hydrazones and their chelates in solution. 


\section{Experimental}

\section{Physical measurements}

Elemental (carbon, hydrogen and nitrogen) analyses were carried out on W.C. Heraeus Hanau elemental analyzer and Perkin-Elmer $2400 \mathrm{CHN}$ elemental analyzer at the Microanalytical Center, Cairo University, Giza, Egypt. IR spectra (4000-400 $\left.\mathrm{cm}^{-1}\right)$ were recorded on a Bruker Vector 22 spectrometer (Germany) using $\mathrm{KBr}$ pellets. Electronic spectra were recorded on a Jasco $\mathrm{V}-550 \mathrm{UV} / \mathrm{Vis}$ spectrophotometer. ${ }^{1} \mathrm{H}$ NMR spectra in DMSO- $d_{6}$, were recorded on a Varian Gemini $200 \mathrm{MHz}$ spectrometer at room temperature using TMS as an internal standard. Mass spectra were recorded at $70 \mathrm{eV}$ on a gas chromatographic GCMSqp 1000-ex Shimadzu mass spectrometer. Melting points were determined using Rumo 3600 melting point apparatus.

\section{Potentiometric measurements}

Appropriate aliquots of standard solutions of metal nitrates $\left(0.0015 \mathrm{~mol} \mathrm{~L}^{-1}\right)$ and ligands $\left(0.003 \mathrm{~mol} \mathrm{~L}^{-1}\right)$ were titrated potentiometrically with $0.09 \mathrm{~mol} \mathrm{~L}^{-1} \mathrm{KOH}$ solution. For each mixture, the total volume was made up to $30 \mathrm{~mL}$ by adding the organic solvent and water to attain the desired medium composition. The ionic strength of the medium $\left(\mathrm{KNO}_{3}\right)$ was kept virtually constant at $0.05 \mathrm{~mol} \mathrm{~L}^{-1}$. The values of $\mathrm{pH}$ 's were recorded on a pH-meter(DIGI-520 Germany) fitted with a combined glass-calomel electrode with an accuracy of \pm 0.01 units. The temperature was maintained constant by using an ultrathermostat (U3 Julabo-Germany). Purified nitrogen was bubbled through the titrating solutions to keep inert atmosphere. The measured $\mathrm{pH}$ values were corrected.

\section{Preparation of hydrazones}

To an ethanolic solution of 2-hydrazino-4-methylquinoline $(0.01 \mathrm{~mol})$, benzil, biacetylmonoxime or $o$ hydroxyacetophenone $(0.012 \mathrm{~mol})$ was added. The reaction mixture was refluxed for $1 / 2 \mathrm{~h}$ to yield 2 -[ $\alpha$ (benzoyl)benzylidinehydrazino]-4-methylquinoline (BHQ), 2-[ $\alpha$-(acetyloxime)ethylidinehydrazino]-4methylquinoline (MHQ) or 2-[ $\alpha$-(o-hydroxyphenyl) ethylidinehydrazino]-4-methylquinoline (AHQ), respectively. After cooling, the formed compounds were filtered off, washed with ether and crystallized from ethanol. The results of elemental analyses, $\%$ yield, colour and melting points $\left({ }^{\circ} \mathrm{C}\right)$ are shown in Table 1 .
Table 1. Analytical and physical data of the hydrazones

\begin{tabular}{|c|c|c|c|c|c|c|}
\hline \multirow{2}{*}{$\begin{array}{l}\text { Compound } \\
\text { M.F. } \\
\text { (F.Wt.) }\end{array}$} & \multicolumn{3}{|c|}{$\begin{array}{c}\text { Elemental Analysis } \\
\% \text { Found / (Calc.) }\end{array}$} & \multirow[t]{2}{*}{ Colour } & \multirow[t]{2}{*}{$\begin{array}{l}\text { Yield } \\
(\%)\end{array}$} & \multirow[t]{2}{*}{$\begin{array}{l}\mathrm{mp} \\
\left({ }^{\circ} \mathrm{C}\right)\end{array}$} \\
\hline & $\mathrm{C}$ & $\mathrm{H}$ & $\mathrm{N}$ & & & \\
\hline $\begin{array}{l}\mathrm{BHQ} \\
\mathrm{C}_{24} \mathrm{H}_{19} \mathrm{~N}_{3} \mathrm{O} \\
(365)\end{array}$ & $\begin{array}{c}78.45 \\
(78.90)\end{array}$ & 5.41 & $\begin{array}{c}11.90 \\
(11.51)\end{array}$ & $\begin{array}{c}\text { Yellowish- } \\
\text { Orange }\end{array}$ & 65 & 165 \\
\hline $\begin{array}{l}\text { MHQ } \\
\mathrm{C}_{14} \mathrm{H}_{16} \mathrm{~N}_{4} \mathrm{O} \\
(256)\end{array}$ & $\begin{array}{c}65.60 \\
(65.63)\end{array}$ & $\begin{array}{c}6.10 \\
(6.25)\end{array}$ & $\begin{array}{l}21.82 \\
(21.88)\end{array}$ & Yellow & 70 & 224 \\
\hline $\begin{array}{l}\mathrm{AHQ} \\
\mathrm{C}_{17} \mathrm{H}_{15} \mathrm{~N}_{3} \mathrm{O} \\
(277)\end{array}$ & 73.49 & (5.42) & $\begin{array}{c}14.89 \\
(15.16)\end{array}$ & Yellow & 60 & 158 \\
\hline
\end{tabular}

\section{Results and Discussion}

\section{Choice of the proligands}

The proligands were chosen to probe and examine the effect of the following: ( $i$ ) nature of donor atoms, ( $i i)$ chelate ring size, (iii) rigidity of the structure caused by the presence of the benzene ring (AHQ) and (iv) presence of hydrophobic phenyl groups (BHQ) and hydrophilic methyl groups (MHQ) in the side chain. This could be illustrated as shown in Scheme 2:<smiles>[Y14]Cn1/c(=N\N)cc(C)c2ccccc21</smiles>

HQ (NN-donor); one 5-membered chelate ring<smiles></smiles>

BHQ (NNO-donor)

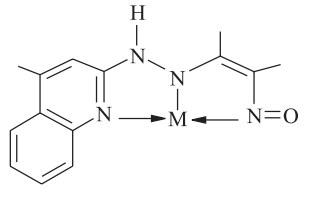

MHQ (NNN-donor) Two 5-membered chelate rings<smiles></smiles>

MHQ (NNO-donor)<smiles></smiles>

AHQ (NNO-donor)
Two chelate rings (one 5- and one 6-membered chelate rings)

Scheme 2. Chelating ability of the hydrazones.

\section{Characterization of the hydrazones}

Structures of the proligands have been elucidated by elemental analyses, UV-Vis, IR, Mass and ${ }^{1} \mathrm{H}$ NMR spectra. 
The results of elemental analyses are in good agreement with the proposed formulae (Table 1). The electronic absorption spectra of the hydrazones in dioxane exhibit two intense bands in the 228 - 245 and 310 - $348 \mathrm{~nm}$ regions. These bands are characterized by high molar absorptivity ( $\varepsilon=33660-12700$ $\mathrm{L} \mathrm{mol}^{-1} \mathrm{~cm}^{-1}$ ), so they are of $\pi-\pi *$ transition type. The higher energy bands at 228-245 $\mathrm{nm}$ are consistent with those reported for the aromatic quinoline ring. ${ }^{14}$ On the other hand, the medium energy bands at 310-348 nm may be due to charge transfer transitions involving the whole molecule. In addition, shoulders at $360-416 \mathrm{~nm}$ are assignable to $n-\pi^{*}$ transitions of the carbonyl and/or azomethine groups. The IR spectra of all hydrazones showed very strong bands at 1614-1602 $\mathrm{cm}^{-1}$ and 3344-3263 $\mathrm{cm}^{-1}$ which are attributed to $v(\mathrm{C}=\mathrm{N})$ and $v(\mathrm{NH})$ respectively. The strong band at $1646 \mathrm{~cm}^{-1}$ is assigned to $v(\mathrm{C}=\mathrm{O})$ of the $\mathrm{BHQ}$, suggesting its ketonic nature. On the other hand, the broad bands centered at 2727 and $2807 \mathrm{~cm}^{-1}$ are assignable to $\mathrm{v}(\mathrm{OH}-\mathrm{N})$ of the phenolic (AHQ) and oximic (MHQ) groups, respectively. The mass spectra of the MHQ and BHQ hydrazones showed molecular ion and base peaks at m/e (256 and 198) and (365 and 260) respectively, which coincide with their formulae weights. The ${ }^{1} \mathrm{H}$ NMR spectrum of MHQ hydrazone relative to TMS in DMSO- $d_{6}$ lends further support to the suggested structure (Scheme 3).

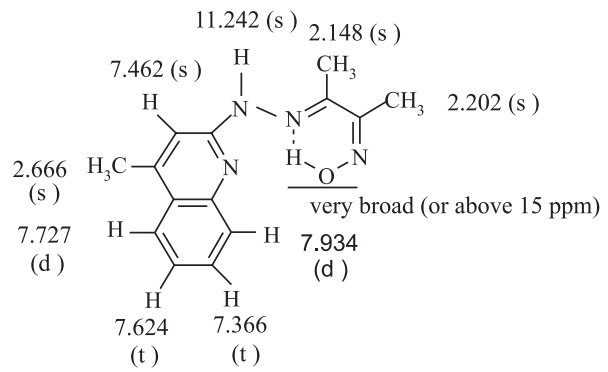

$$
\begin{aligned}
& s=\text { singlet } \\
& d=\text { doublet } \\
& t=\text { triplet }
\end{aligned}
$$$$
\text { (t) } \quad(\mathrm{t})
$$

Scheme 3.

\section{Potentiometric titration curves}

Representative $\mathrm{pH}$-metric titration curves of the free and complexed hydrazones in $75 \%$ (v/v) dioxane-water at $303 \mathrm{~K}$ are shown in Figure 1. Inspection of the titration curves reveals the following : (i) All hydrazones dissociate only one proton between $\mathrm{a}=0.0$ and $\mathrm{a}=1.0$ in absence and presence of different metal ions $(\mathrm{a}=$ number of moles of $\mathrm{KOH} /$ mole of hydrazone). This suggests that all hydrazones behave as monobasic species towards the metal ions; (ii) In case of $\mathrm{Mn}^{\mathrm{II}}, \mathrm{Ni}^{\mathrm{II}}, \mathrm{Cu}^{\mathrm{II}}-\mathrm{BHQ} / \mathrm{AHQ}, \mathrm{Mn}^{\mathrm{II}}, \mathrm{Co}^{\mathrm{II}}-\mathrm{MHQ}$, $\mathrm{Zn}^{\mathrm{II}}-\mathrm{AHQ}$ and $\mathrm{Th}^{\mathrm{IV}}$-HQ chelates, two sharp inflections at $\mathrm{m}=1.0$ and $\mathrm{m}=2.0$ were observed $(\mathrm{m}=$ number of moles of $\mathrm{KOH} /$ mole of metal ion). The two inflections correspond to the stepwise formation of mono- and bis-chelates, respectively . This behaviour is consistent with the higher values of $\mathrm{K}_{1} / \mathrm{K}_{2}$ (Table 2); (iii) The above feature was not observed with the other metal cations, where only one overlapping buffer region between $\mathrm{m}=0.0$ to $\mathrm{m}=2.0$ was obtained, corresponding to the formation of bis chelates directly. Also, this is consistent with lower values of $\mathrm{K}_{1} / \mathrm{K}_{2}$ (Table 2); (iv) The formation constants of $\mathrm{Cu}^{\mathrm{II}}-\mathrm{MHQ}$ can not be determined potentiometrically due to the precipitation of the solid complex (green crystals) even at low concentration before beginning of the titration.
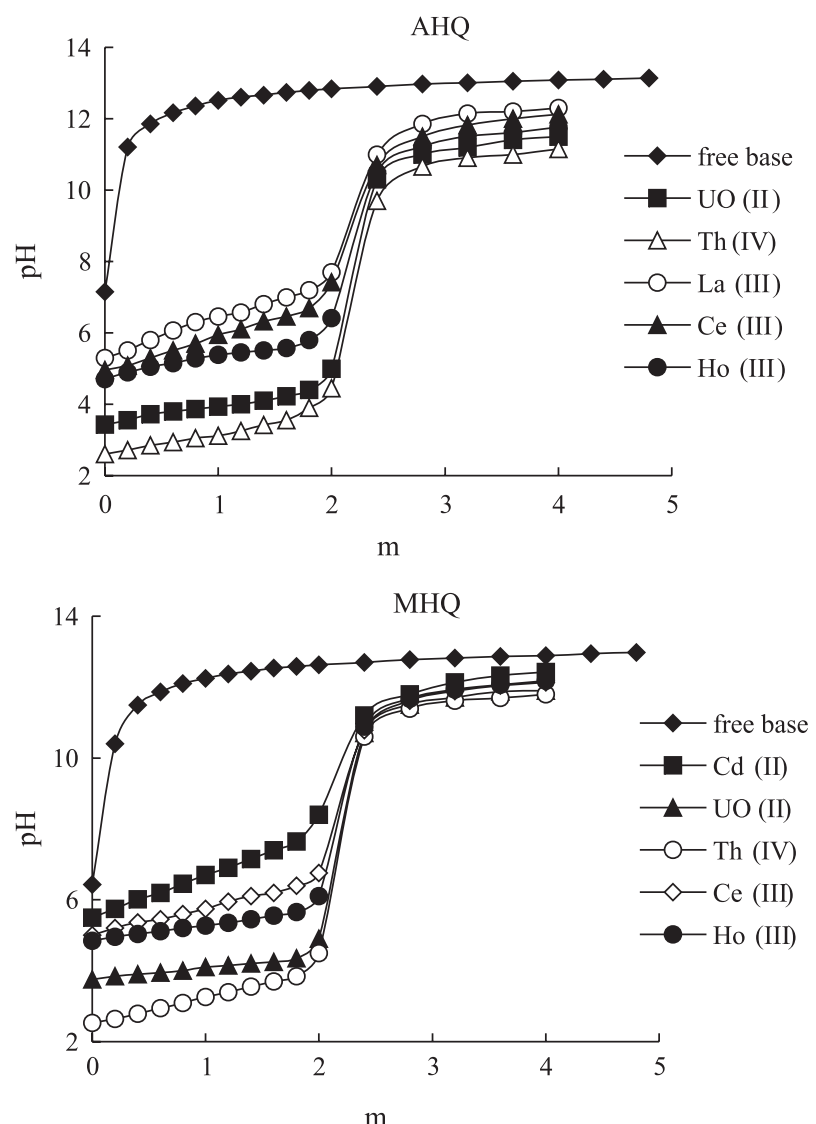

Figure 1. pH-Metric titration curves of AHQ and MHQ in presence and absence of metal ions in 75\% (v/v) dioxane-water at 303K.

\section{Dissociation constants}

The dissociation constants of the hydrazones were calculated by using the relationship:

$\mathrm{pK}^{\mathrm{H}}=\mathrm{pH}-\log \frac{\mathrm{aC}_{\mathrm{L}}+\left[\mathrm{H}^{+}\right]-\left[\mathrm{OH}^{-}\right]}{(1-\mathrm{a}) \mathrm{C}_{\mathrm{L}}-\left[\mathrm{H}^{+}\right]+\left[\mathrm{OH}^{-}\right]}$

where, " $\mathrm{C}_{\mathrm{L}}$ " represents the total concentration of the hydrazone and "a" represents the number of moles of base added per mole of hydrazone. The dissociated proton is that either of the phenolic (AHQ), oximic (MHQ) or belongs to the $-\mathrm{NH}$ at the quinoline ring. In general, the high basicity of the hydrazones may be attributed to the 
presence of strong intramolecular H-bonding especially in less polar medium, $75 \%$ (v/v) dioxane-water. The inhibition of the second dissociation in case of AHQ and MHQ is due to the fact that the first ionization increases the electron density on the whole conjugated system and results in a more stable structure. The values of $\mathrm{pK}^{\mathrm{H}}$ 's in 75\% (v/v) dioxane-water: 12.89 (HQ), 12.77 (BHQ), 12.45 (MHQ) and 12.70 (AHQ) are close to those reported in literature ${ }^{8,10,12}$ for similar hydrazones under the same experimental conditions.

\section{Stability constants}

The calculation of the stability constants $\left(\log \mathrm{K}_{1}\right.$ and $\log \mathrm{K}_{2}$ ) of the investigated metal complexes is based on the fact that the $\mathrm{pH}$-measurements during the titration of a ligand solution in presence and in absence of a metal ion could be used to calculate the free base exponent (pL) and the number of ligand molecules attached per metal ion ( $\tilde{\mathrm{n}})$. The Irving-Rossotti relations:

$\log (\tilde{\mathrm{n}} / 1-\tilde{\mathrm{n}})=\log \mathrm{K}_{1}-\mathrm{pL}$ and $\log (\tilde{\mathrm{n}}-1 / 2-\tilde{\mathrm{n}})=\log \mathrm{K}_{2}-\mathrm{pL}$

have been constructed and analyzed to determine $\log \mathrm{K}_{1}$ and $\log \mathrm{K}_{2}$, respectively. The interaction of the studied proligands with some divalent $3 \mathrm{~d}$ transition metal ions ( $\mathrm{Mn}^{\mathrm{II}}$, $\mathrm{Co}^{\mathrm{II}}, \mathrm{Ni}^{\mathrm{II}}$ and $\mathrm{Cu}^{\mathrm{II}}$ ), non transition $3 \mathrm{~d}$ and $4 \mathrm{~d}$ metal ions $\left(\mathrm{Zn}^{\mathrm{II}}\right.$ and $\left.\mathrm{Cd}^{\mathrm{II}}\right)$, trivalent $4 \mathrm{f}$ lanthanide metal ions $\left(\mathrm{La}^{\mathrm{III}}, \mathrm{Ce}^{\mathrm{III}}\right.$, $\mathrm{Sm}^{\mathrm{III}}$ and $\mathrm{Ho}^{\mathrm{III}}$ ) and $5 f$ actinide metal ions $\left(\mathrm{UO}_{2}{ }^{\mathrm{II}}\right.$ and $\mathrm{Th}^{\mathrm{IV}}$ ) has been studied potentiometrically in $75 \%(\mathrm{v} / \mathrm{v})$ dioxanewater at $303 \mathrm{~K}$ using $0.05 \mathrm{~mol} \mathrm{~L}^{-1} \mathrm{KNO}_{3}$ as a supporting electrolyte. The stability constants are summarized in Table 2. Inspection of the data reveals the following:

(i) $\mathrm{K}_{1} / \mathrm{K}_{2}>1.0$ for most complexes especially $3 \mathrm{~d}$ and $4 \mathrm{~d}$ complexes, indicating that the vacant sites of the metal ions are more freely available for binding the first hydrazone than for a second one i.e. there is some steric hindrance for the second coordination; (ii) $\left(\mathrm{K}_{1} / \mathrm{K}_{2}\right)<1.0$ for $\mathrm{UO}_{2}{ }^{\text {II }}$ and most lanthanide (III) complexes, suggesting their higher preference for the second coordination which is consistent with their higher coordination numbers $(8-10)$; (iii) $\left(\mathrm{K}_{1} / \mathrm{K}_{2}\right)$ has abnormal high values (Table 2 ) especially for $\mathrm{Mn}^{\mathrm{II}}-\mathrm{BHQ}$ and $\mathrm{Cu}^{\mathrm{II}}-\mathrm{AHQ}$ complexes, suggesting either a higher steric hindrance (BHQ is a bulky ligand and AHQ is a more rigid ligand) for the second coordination or a change in the dentate character of the ligands from tridentate in 1:1 to bidentate in 1:2 M:L chelates. The latter is consistent with either (a) the greater tendency of $\mathrm{Mn}^{\mathrm{II}}$ and $\mathrm{Cu}^{\mathrm{II}}$ ions to form tetra-coordinated species (tetrahedral $\mathrm{Mn}^{\mathrm{II}}$ and square planar $\mathrm{Cu}^{\mathrm{II}}$ - chelates) or (b) a large gain of entropy; (iv) The unexpected high stability constants of $\mathrm{Mn}^{\mathrm{II}}$-chelates (Table 2), suggest either an oxidation or spin pairing as a result of complexation of such class of hydrazones (bearing the quinoline ring) with $\mathrm{Mn}^{\mathrm{II}}$ ions. However, such behaviour is not observed with other hydrazones; $;^{7,8}(v)$ The high stability of $\mathrm{Ln}^{\mathrm{III}}$-AHQ chelates $(\mathrm{Ln}=\mathrm{La}, \mathrm{Ce}, \mathrm{Sm}$ and $\mathrm{Ho}$ ) is consistent with the high affinity of lanthanides for $\mathrm{O}$ donors especially phenolate and carboxylate, ${ }^{15}$ (vi) For transition metal complexes $\log \beta_{2}$ has the order:

$\mathrm{Cu}^{\mathrm{II}}>\mathrm{Co}^{\mathrm{II}}>\mathrm{Ni}^{\mathrm{II}}>\mathrm{Zn}^{\mathrm{II}}>\mathrm{Cd}^{\mathrm{II}}$

In case of $\mathrm{BHQ}, \mathrm{Co}^{\mathrm{II}}$ and $\mathrm{Ni}^{\mathrm{II}}$-complexes show reverse order. The above order indicates that Irving-Williams rule is not strictly obeyed. The higher stability of $\mathrm{Cu}^{\mathrm{II}}$ - complexes is due to Jahn-Teller distortion and the lower stability of $\mathrm{Zn}^{\mathrm{II}}$ and $\mathrm{Cd}^{\mathrm{II}}$ - complexes is consistent with their $\mathrm{CFSE}=0$, $\mathrm{Zn}^{\mathrm{II}}$ and $\mathrm{Cd}^{\mathrm{II}}$ are $\mathrm{d}^{10}$ - systems; (vii) For lanthanide (III) and actinide-complexes, $\log \beta_{2}$ has the order:

$\mathrm{Th}^{\mathrm{IV}}>\mathrm{UO}_{2}{ }^{\mathrm{II}}>\mathrm{Ho}^{\mathrm{III}}>\mathrm{Sm}^{\mathrm{III}}>\mathrm{Ce}^{\mathrm{III}}>\mathrm{La}^{\mathrm{III}}$

Table 2. Stability constants and $\mathrm{K}_{1} / \mathrm{K}_{2}$ for the complexes in $75 \%(\mathrm{v} / \mathrm{v})$ dioxane - water at $303 \mathrm{~K}$

\begin{tabular}{|c|c|c|c|c|c|c|c|c|c|c|c|c|c|c|c|c|}
\hline \multirow[t]{2}{*}{ Complex } & \multicolumn{4}{|c|}{ HQ } & \multicolumn{4}{|c|}{ BHQ } & \multicolumn{4}{|c|}{ MHQ } & \multicolumn{4}{|c|}{ AHQ } \\
\hline & $\log \mathrm{K}_{1}$ & $\log \mathrm{K}_{2}$ & $\log \beta_{2}$ & $\mathrm{~K}_{1} / \mathrm{K}_{2}$ & $\log \mathrm{K}_{1}$ & $\log \mathrm{K}_{2}$ & $\log \beta_{2}$ & $\mathrm{~K}_{1} / \mathrm{K}_{2}$ & $\log \mathrm{K}_{1}$ & $\log \mathrm{K}_{2}$ & $\log \beta_{2}$ & $\mathrm{~K}_{1} / \mathrm{K}_{2}$ & $\log \mathrm{K}_{1}$ & $\log \mathrm{K}_{2}$ & $\log \beta_{2}$ & $\mathrm{~K}_{1} / \mathrm{K}_{2}$ \\
\hline $\mathrm{pK}^{\mathrm{H}}$ & 12.89 & - & - & - & 12.77 & - & - & - & 12.45 & - & - & - & 12.70 & - & - & - \\
\hline $\mathrm{Mn}^{\mathrm{II}}$ & 8.71 & 8.43 & 17.14 & 1.91 & 11.73 & 8.97 & 20.70 & 575.44 & 10.37 & 8.98 & 19.35 & 24.55 & 10.92 & 9.09 & 20.01 & 67.61 \\
\hline $\mathrm{Co}^{\mathrm{II}}$ & 8.98 & 8.25 & 17.23 & 5.37 & 10.44 & 9.39 & 19.83 & 11.22 & 10.95 & 9.12 & 20.07 & 67.61 & 10.57 & 10.42 & 20.99 & 1.41 \\
\hline $\mathrm{Ni}^{\mathrm{II}}$ & 8.74 & 8.25 & 16.99 & 3.09 & 10.98 & 9.45 & 20.43 & 33.88 & 9.84 & 9.10 & 18.94 & 5.50 & 11.07 & 8.95 & 20.02 & 131.83 \\
\hline $\mathrm{Cu}^{\mathrm{II}}$ & 11.82 & 10.79 & 22.61 & 10.72 & 11.96 & 10.49 & 22.45 & 29.51 & - & - & - & - & 12.16 & 9.46 & 21.62 & 501.19 \\
\hline $\mathrm{Zn}^{\mathrm{II}}$ & 8.51 & 8.29 & 16.80 & 1.66 & 9.86 & 9.64 & 19.50 & 1.66 & 9.34 & 9.16 & 18.50 & 1.51 & 10.57 & 8.50 & 19.07 & 117.49 \\
\hline $\mathrm{Cd}^{\mathrm{II}}$ & 7.83 & 7.21 & 15.04 & 4.17 & 9.00 & 8.32 & 17.32 & 4.79 & 8.72 & 8.07 & 16.79 & 4.47 & 9.11 & 8.52 & 17.63 & 3.89 \\
\hline $\mathrm{UO}_{2}{ }^{\mathrm{II}}$ & 10.40 & 9.49 & 19.89 & 8.13 & 11.33 & 11.51 & 22.84 & 0.66 & 10.90 & 11.11 & 22.01 & 0.62 & 11.34 & 11.43 & 22.77 & 0.81 \\
\hline $\mathrm{Th}^{2 \mathrm{IV}}$ & 12.14 & 10.63 & 22.77 & 32.36 & 12.53 & 12.80 & 25.33 & 0.54 & 11.96 & 11.72 & 23.68 & 1.74 & 12.19 & 12.11 & 24.30 & 1.20 \\
\hline $\mathrm{La}^{\mathrm{III}}$ & 8.47 & 8.36 & 16.83 & 1.29 & - & - & - & - & 9.36 & 8.93 & 18.29 & 2.69 & 9.15 & 8.72 & 17.87 & 2.69 \\
\hline $\mathrm{Ce}^{\mathrm{III}}$ & 8.78 & 8.80 & 17.58 & 0.96 & 9.29 & 9.10 & 18.39 & 1.55 & 9.42 & 9.19 & 18.61 & 1.70 & 9.68 & 9.23 & 18.91 & 2.82 \\
\hline $\mathrm{Sm}^{\mathrm{III}}$ & 8.98 & 9.19 & 18.17 & 0.62 & 9.56 & 9.68 & 19.24 & 0.76 & 9.42 & 9.39 & 18.81 & 1.07 & 9.85 & 9.56 & 19.41 & 1.95 \\
\hline $\mathrm{Ho}^{\mathrm{III}}$ & 9.30 & 9.42 & 18.72 & 0.76 & 9.89 & 9.98 & 19.87 & 0.81 & 9.75 & 9.85 & 19.60 & 0.79 & 9.98 & 10.04 & 20.02 & 0.87 \\
\hline
\end{tabular}


This order is consistent with the higher charge on $\mathrm{Th}^{\mathrm{IV}}$ ion, the smallest ionic size of $\mathrm{Ho}^{\mathrm{III}}, 0.89 \AA$, and the largest ionic size of $\mathrm{La}^{\mathrm{III}}, 1.06 \AA$. However, a number of attempts have been made to find general relationships which affect the stability of the chelates.

\section{Basicity of the ligands}

In an attempt to study the dependence of the stability of the chelates on the basicity of the ligands, IrvingRossotti $^{16}$ derived a relationship between the logarithms of the stability constants for metal complexes of a similar pair of ligands $\mathrm{A}$ and $\mathrm{B}$ :

$\log \mathrm{K}^{\mathrm{MA}}=\log \mathrm{K}^{\mathrm{MB}}+\left(\log \mathrm{K}^{\mathrm{HA}}-\log \mathrm{K}^{\mathrm{HB}}\right)$

Therefore, a high correlation between the stability constants of the chelates $(\log \mathrm{K})$ and the basicity of the ligands $\left(\mathrm{pK}^{\mathrm{H}}\right)$ is expected. By using the linear regression analysis (LRA), the following relations were obtained in $75 \%(\mathrm{v} / \mathrm{v})$ dioxane-water at $303 \mathrm{~K}$ :

$$
\begin{array}{lc}
\log \mathrm{K}_{1}\left(\mathrm{UO}_{2}{ }^{\mathrm{II}} \text {-chelates }\right)=-7.2+1.45 \mathrm{pK}^{\mathrm{H}} & \mathrm{r}=0.974 \\
\log \mathrm{K}_{2}\left(\mathrm{UO}_{2}{ }^{\mathrm{II}} \text {-chelates }\right)=-45.5+1.26 \mathrm{pK}^{\mathrm{H}} & \mathrm{r}=0.9998 \\
\log \mathrm{K}_{1}\left(\mathrm{Th}^{\mathrm{IV}} \text {-chelates }\right)=-7.4+1.55 \mathrm{pK}^{\mathrm{H}} & \mathrm{r}=0.911 \\
\log \mathrm{K}_{2}\left(\mathrm{Th}^{\mathrm{IV}} \text {-chelates }\right)=-24.4+2.89 \mathrm{pK}^{\mathrm{H}} & \mathrm{r}=0.890
\end{array}
$$

Furthermore, the same method (LRA) was applied for $\mathrm{Co}^{\mathrm{II}}$-MHQ chelates at different mole fractions of ethanol at $303 \mathrm{~K}$ (see Table 4). Also, the following relations were obtained:

$$
\begin{aligned}
& \log \mathrm{K}_{1}\left(\mathrm{Co}^{\mathrm{II}}-\mathrm{MHQ}\right)=-13.6+2.23 \mathrm{pK}^{\mathrm{H}}(\mathrm{MHQ}) \mathrm{r}=0.999 \\
& \log \mathrm{K}_{2}\left(\mathrm{Co}^{\mathrm{II}}-\mathrm{MHQ}\right)=-14.6+2.30 \mathrm{pK}^{\mathrm{H}}(\mathrm{MHQ}) \mathrm{r}=0.998
\end{aligned}
$$

In another attempt, the following relations were obtained:

$$
\begin{array}{ll}
\log \mathrm{K}_{1}(\mathrm{MHQ})=2.33+0.74 \log \mathrm{K}_{1}(\mathrm{BHQ}) & \mathrm{r}=0.877 \\
\log \mathrm{K}_{2}(\mathrm{MHQ})=1.60+0.81 \log \mathrm{K}_{2}(\mathrm{BHQ}) & \mathrm{r}=0.983 \\
\log \mathrm{K}_{1}(\mathrm{AHQ})=2.25+0.80 \log \mathrm{K}_{1}(\mathrm{BHQ}) & \mathrm{r}=0.951 \\
\log \mathrm{K}_{2}(\mathrm{AHQ})=1.79+0.80 \log \mathrm{K}_{2}(\mathrm{BHQ}) & \mathrm{r}=0.871
\end{array}
$$

The above relations validate the Irving-Rossotti equation ${ }^{16}$ and confirm that the basicity of the ligands is a main factor governing the stability of the chelates for a series of closely related ligands.

\section{Hardness/softness}

According to our previous work, a significant comparison of the formation constant $\left(\log \mathrm{K}_{1}\right)$ must be made for some similar hydrazones bearing the triazine, ${ }^{17,18}$ pyridazine, ${ }^{11,12}$ pyrimidine ${ }^{8}$ and quinoline rings (this study) under the same experimental conditions. Inspection of the data reveals that the order of stability and hence reactivity towards metal ions is as follows:

Triazine $>$ Pyridazine $>$ Quinoline $>$ Pyrimidine,

which is consistent with increasing the electron density on the heterocyclic ring. This provides strong evidence that the $\mathrm{N}$-atom of the heterocyclic ring participates in chelation.

\section{Chelate effect}

The investigated hydrazones BHQ, MHQ and AHQ can form chelate rings and act as tridentate (NNO or NNN) donors as shown in Scheme 2. In general, the higher stability of such systems compared to the parent hydrazino HQ compound (NN-donor) is attributed to the formation of two chelate rings and also the resonance within these chelate rings which stabilize the formed chelates. The effect of such chelate ring size can be illustrated by comparing $\log \mathrm{K}_{1}$ (HQ-chelates) which form one

\begin{tabular}{|c|c|c|c|c|c|c|c|}
\hline \multirow[t]{2}{*}{ Complex } & \multicolumn{4}{|c|}{$\log \mathrm{K}_{1}$} & \multicolumn{3}{|c|}{$\log \mathrm{K}_{1}(\mathrm{str})$} \\
\hline & HQ & BHQ & MHQ & AHQ & BHQ & MHQ & AHQ \\
\hline $\mathrm{Mn}^{\mathrm{II}}$ & 8.71 & 11.73 & 10.37 & 10.92 & 3.02 & 1.66 & 2.21 \\
\hline $\mathrm{Co}^{\mathrm{II}}$ & 8.98 & 10.44 & 10.95 & 10.57 & 1.46 & 1.97 & 1.59 \\
\hline $\mathrm{Ni}^{\mathrm{II}}$ & 8.74 & 10.98 & 9.84 & 11.07 & 2.24 & 1.10 & 2.33 \\
\hline $\mathrm{Cu}^{\mathrm{II}}$ & 11.82 & 11.96 & - & 12.16 & 0.14 & - & 0.34 \\
\hline $\mathrm{Zn}^{\mathrm{II}}$ & 8.51 & 9.86 & 9.34 & 10.57 & 1.35 & 0.83 & 2.06 \\
\hline $\mathrm{Cd}^{\mathrm{II}}$ & 7.83 & 9.00 & 8.72 & 9.11 & 1.17 & 0.89 & 1.28 \\
\hline $\mathrm{UO}_{2}{ }^{\mathrm{II}}$ & 10.40 & 11.33 & 10.90 & 11.34 & 0.93 & 0.50 & 0.94 \\
\hline $\mathrm{Th}^{\mathrm{IV}}$ & 12.14 & 12.53 & 11.96 & 12.19 & 0.39 & -0.18 & 0.05 \\
\hline
\end{tabular}
5 -membered chelate ring with $\log \mathrm{K}_{1}$ (hydrazone chelates) which form two chelate rings (Scheme 2 and Table 3). The data showed that $\log \mathrm{K}_{1}$ (str) is positive and ranges from 0.05-2.33 for all systems except $\mathrm{Th}^{\mathrm{IV}}$-MHQ chelate (-0.18) and Mn' ${ }^{\mathrm{II}}-\mathrm{BHQ}$ chelate (3.02).

\section{Effect of the reaction medium}

The solvent characteristics such as H-bonding, dispersion forces, dielectric constants (D), donor numbers

Table 3. $\log \mathrm{K}_{1}$ (str) for some Hydrazone-complexes 
(DN) and acceptor numbers (AN) may affect both the dissociation constants of the hydrazones and the stability constants of their chelates. In order to provide an explanation of the dependence of $\mathrm{pK}^{\mathrm{H}}$ and $\log \mathrm{K}$ on the solvent parameters, the $\mathrm{pK}^{\mathrm{H}}$ 's of the MHQ hydrazone and $\log \mathrm{K}$ of its $\mathrm{Co}^{\mathrm{II}}$-chelates were determined $\mathrm{pH}$-metrically in $75 \%(\mathrm{v} / \mathrm{v})$ solvent (dioxane, isopropanol, ethanol and methanol)-water at $303 \mathrm{~K}$ as well as at different compositions of ethanol: 55, 60, 65, 70 and $75 \%(\mathrm{v} / \mathrm{v})$ ethanol-water at $303 \mathrm{~K}$ (Table 4). Inspection of the data given in Table 4 reveals that: $(i)$ the dissociation of the MHQ hydrazone increases (i.e., lower $\mathrm{pK}^{\mathrm{H}}$ values) in more polar media, e.g. $75 \%$ (v/v) alcohol-water. Consequently, lower stability constants are obtained in such media (media having higher dielectric constants, acceptor numbers and lower mole fraction of solvents); (ii) The stability of the cobaloxime in $75 \%$ solvent-water decreases in the sequence:

Dioxane $>$ Isopropanol $>$ Ethanol $>$ Methanol

(iii) The order of stability at various ethanol-water (v/v) is as follows:

$75 \%>70 \%>65 \%>60 \%>55 \%$

These orders agree with orders of decreasing both the basicity of the ligand and the mole fraction of ethanol and increasing both the dielectric constant of the medium and the coordinating ability of the solvent. Generally, polar solvents having higher dielectric constants increase the solvation of both the cation $\left(\mathrm{H}^{+}\right)$and the anion $\left(\mathrm{L}^{-}\right)$which in turn increases the distance of closest approach of the ions. Therefore, the solvated ions increase the dissociation process leading to lower $\mathrm{pK}^{\mathrm{H}}$ values and hence lower $\log \mathrm{K}$ values; the strong coordinating ability of the polar solvents retards the metal-ligand interaction via metal-solvent associations. ${ }^{19}$ Since the ligands are insoluble in water and in an attempt to determine the dissociation constants of the MHQ and the stability constants of its cobaloximes in aqueous medium, a LRA of $\mathrm{pK}^{\mathrm{H}}, \log \mathrm{K}_{1}$ or $\log \mathrm{K}_{2}$ vs. 1/D $(\operatorname{method} A) ; A N(\operatorname{method} B)$ or $X_{i}($ method C, Figure 2) was constructed and analyzed (Table 4). The obtained data by these different methods are in fair agreement. It is evident that the donor numbers of the solvents do not provide the correlation. In conclusion, the stability of the chelates increases by increasing the organic solvent content, i.e., the mole fraction of solvent and decreasing both the dielectric constant of the medium and the acceptor number of the solvent.
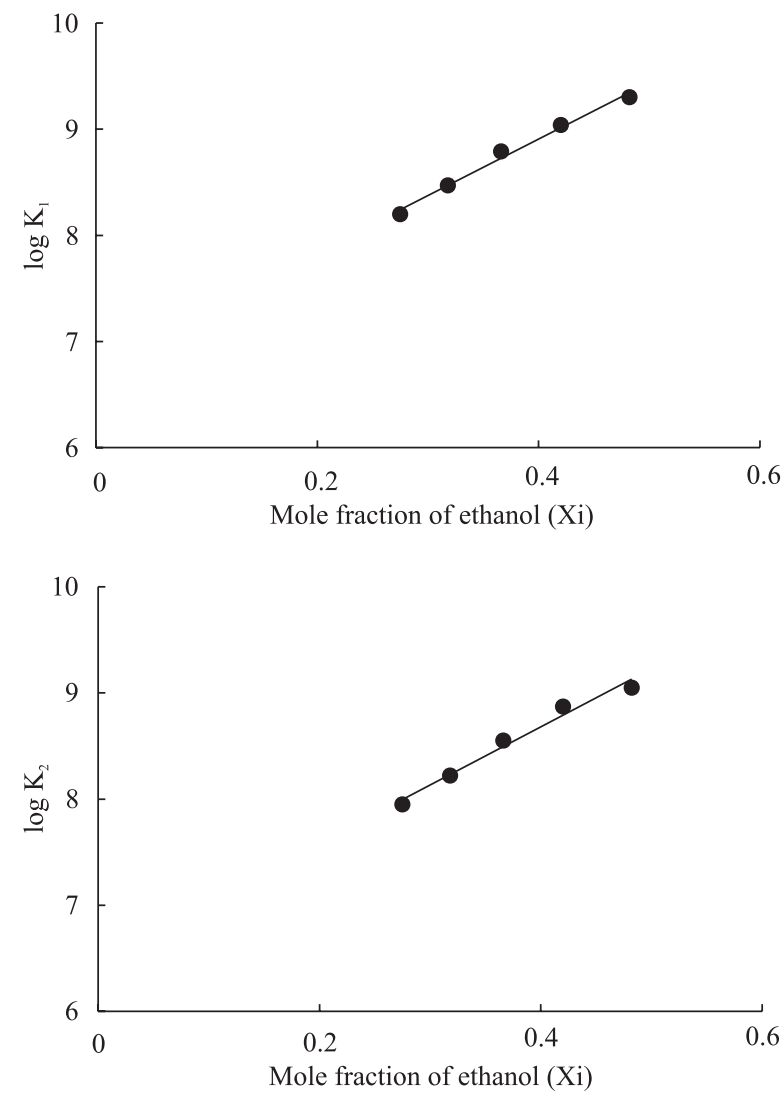

Figure 2. $\log \mathrm{K} v$. mole fraction of ethanol for cobaloxime complexes.

Table 4. Stability constants* of the cobaloxime ( $\left.\mathrm{Co}^{\mathrm{II}}-\mathrm{MHQ}\right)$ complexes in various solvent-water (v/v) compositions at $303 \mathrm{~K}$

\begin{tabular}{|c|c|c|c|c|c|c|c|c|c|c|c|}
\hline \multirow[t]{3}{*}{$\log \mathrm{K}$} & \multicolumn{10}{|c|}{ Solvent Composition\% (v/v) } & \multirow{3}{*}{$\begin{array}{c}\text { Dioxane } \\
75\end{array}$} \\
\hline & \multicolumn{8}{|c|}{ Ethanol } & \multirow{2}{*}{$\begin{array}{c}\text { Methanol } \\
75\end{array}$} & \multirow{2}{*}{$\begin{array}{c}\text { Isopropanol } \\
75\end{array}$} & \\
\hline & $0.00^{\mathrm{a}}$ & $0.00^{\mathrm{b}}$ & $0.00^{\mathrm{c}}$ & 55 & 60 & 65 & 70 & 75 & & & \\
\hline $\mathrm{pK}^{\mathrm{H}}$ & $\begin{array}{c}9.59 \\
(0.989)\end{array}$ & $\begin{array}{c}9.03 \\
(0.989)\end{array}$ & $\begin{array}{c}9.14 \\
(0.996)\end{array}$ & 9.78 & 9.90 & 10.03 & 10.16 & 10.27 & 10.26 & 10.53 & 12.45 \\
\hline $\log \mathrm{K}_{1}$ & $\begin{array}{c}8.84 \\
(0.991)\end{array}$ & $\begin{array}{c}8.42 \\
(0.982)\end{array}$ & $\begin{array}{c}6.77 \\
(0.994)\end{array}$ & 8.20 & 8.47 & 8.79 & 9.04 & 9.30 & 9.18 & 9.87 & 10.95 \\
\hline $\log \mathrm{K}_{2}$ & $\begin{array}{c}8.20 \\
(0.9999)\end{array}$ & $\begin{array}{c}7.44 \\
(0.967)\end{array}$ & $\begin{array}{c}6.49 \\
(0.988)\end{array}$ & 7.95 & 8.22 & 8.55 & 8.87 & 9.05 & 8.81 & 9.58 & 9.12 \\
\hline
\end{tabular}

* Values in parentheses are the correlation coefficients; ${ }^{\mathrm{a}}$ these values were obtained (at $\left.0.0127 ; 1 / \mathrm{D}\right)$ by $\mathrm{LRA}$ of $\operatorname{logK}$ or $\mathrm{pK}^{\mathrm{H}} v s .1 / \mathrm{D}$ of the $75 \%(\mathrm{v} / \mathrm{v})$ solvent-water; ${ }^{\mathrm{b}}$ these values were obtained (at 54.8 ; AN) by LRA of $\log \mathrm{K}$ or $\mathrm{pK}^{\mathrm{H}} v s$. AN of the $75 \%(\mathrm{v} / \mathrm{v})$ solvent-water; ${ }^{\mathrm{c}}$ these values were obtained by LRA of $\log \mathrm{K}$ or $\mathrm{pK}^{\mathrm{H}} v$. the mole fraction $\mathrm{X}_{\mathrm{i}}$ of ethanol. 


\section{Conclusions}

This work describes the complexation and reactivity of several metal ions towards three hydrazones bearing the quinoline ring in solution. Based on the measurement of $\left[\mathrm{H}^{+}\right]$, their stability constants have been evaluated. For the same metal ion, the stability of the chelates is highly affected by the nature of the donor atoms and the medium of the reaction.

\section{References}

1. Craig, J. C.; Edgar, D.; Nature 1955, 34, 176.

2. Issa, R. M.; El-Baradie, H.; Gaber, M.; Egypt J. Chem. 1988, $31,251$.

3. Iskander, M. F.; El-Sayed, L.; Salem, N. M.; Werner, R.; Haase, W.; J. Coord. Chem. 2003, 56,1075.

4. Lever, M.; Anal. Chem. Acta 1973, 65, 311.

5. Nag, I.C.; Chakravorty, A.; Coord. Chem. Rev. 1980, 31, 87.

6. Ramadan, A. T.; Seada, M.; Rizkalla, E.; Monatsh. Chem. 1985, 116, 463.

7. Seleem, H.S.; Annali di Chimica 2003, 93, 305.
8. Seleem, H.S.; El-Shetary, B.A.; Khalil, S.M.E.; Shebl, M.; J. Serb. Chem. Soc. 2003, 68, 729.

9. Khalil, S.M.E.; Seleem, H.S.; El-Shetary, B.A.; Shebl, M.; J. Coord. Chem. 2002, 55, 883.

10. Seleem, H.S.; J. Indian Chem. Soc. 2003, 80, 622.

11. El-Shetary, B.A.; Abdel-Moez , M.S.; Seleem, H.S.; Thermochim. Acta 1987, 113, 21.

12. Abdel-Moez, M.S.; Abu El-Wafa, S.; Seleem, H.S.; El-Shetary, B.A.; Thermochim. Acta 1989, 149, 317.

13. Ramadan, A.A.T.; Eid, M.F.; Seleem, H.S.; Mahmoud, M.M.; Thermochim. Acta 1995, 258, 219.

14. Crews, P.; Rodriguez, J.; Jaspars, M.; Organic Structure Analysis, Oxford University Press: Oxford, 1998.

15. Tei, L.; Blake, A.J.; Wilson, C.; Schrder, M.; J. Chem. Soc., Dalton Trans. 2004, 1945.

16. Irving, H.M.; Rossotti, H.S.; Acta Chem. Scand. 1956, 10, 72.

17. Taha, A.; Synth. React. Inorg. Met.-Org. Chem. 2001, 31, 205.

18. Taha, A.; El-Shetary, B.; Linert, W.; Monatsh. Chem. 1993, 124, 135.

19. Hassaan, A.; Taha, F.; El-Roudi, A.; Quenawy, M.; J. Indian Chem. Soc. 1996, 73, 325. 